\title{
Sepsis y shock séptico: un torbellino de mediadores inflamatorios de difícil manejo terapéutico
}

\author{
H. J. DURÁN GIMÉNEZ-RICO, M.A. ALLER REYERO, L. LORENTE RUIGÓMEZ, \\ L. DURÁN GIMÉNEZ-RICO, J. ARIAS PÉREZ, H. DURÁN SACRISTÁN \\ Departamento de Cirugía. Facultad de Medicina. Universidad Complutense. Madrid
}

\begin{abstract}
SEPSIS AND SEPTIC SHOCK: A TURMOIL OF INFLAMMATORY MEDIATORS WITH A DIFFICULT THERAPEUTIC MANAGEMENT
\end{abstract}

\begin{abstract}
RESUMEN
La sepsis y el shock séptico continúan siendo un capítulo de enorme interés por su elevada frecuencia, y por no existir una disminución en las cifras de mortalidad a pesar de los nuevos conocimientos adquiridos en su fisiopatología y los avances surgidos en los diversos tratamientos aplicados.

El propósito de la presente revisión es actualizar los conceptos presentes en la literatura especializada, tratando de resumir la compleja interacción existente entre diferentes mediadores de doble carácter: exógenos y endógenos, y enunciar las posibles causas por las que los tratamientos novedosos aplicados en la sepsis siguen siendo poco prometedores.
\end{abstract}

\begin{abstract}
Sepsis and septic shock continue being a topic of enormous interest for their high frequency, and for not existing a decrease in the figures of mortality in spite of the new acquired knowledges relationed with their physiopathology and the advances arisen in the diverse applied treat ments.

The purpose of the present study is to update the present notions in the specialized literature, trying to summarize the complex existent inte raction among different mediators of double character: exogenous and endogenous, and to enunciate the possible causes for those that the novel treatments applied in the sepsis continue not to be very promising.
\end{abstract}

PALABRAS CLAVE: Sepsis. Shock séptico. Conferencia de consenso. Mediadores inflamatorios. Endotoxina. Citoquinas proinflamatorias. Citoquinas antiinflamatorias.
KEY WORDS: Sepsis. Septic shock. Consensus conference. Inflamma tory mediators. Endotoxin. Proinflammatory cyotkines. Antiinflamma tory cytokines.

Durán Giménez-Rico HJ, Aller Reyero MA, Lorente Ruigómez L, Durán Giménez-Rico L, Arias Pérez J, Durán Sacristán H. Sepsis y shock séptico: un torbellino de mediadores inflamatorios de difícil manejo terapéutico. An Med Interna (Madrid) 2002; 19: 35-43.

\section{INTRODUCCIÓN}

En los últimos años se ha producido un extraordinario aumento en la incidencia de la sepsis y el shock séptico (1) por lo que nos enfrentamos a un capítulo dentro de la medicina de enorme interés y debate, no sólo ya por su creciente aparición, sino también por tratarse, en los albores del sigo XXI, de un auténtico reto terapéutico pendiente de una solución definitiva. No hay que olvidar que su mortalidad oscila entre el $35-80 \%$ y que ésta, apenas ha variado en las dos últimas décadas a pesar de los enormes progresos en el conocimiento de su fisiopatología y de las novedades curativas y de soporte vital surgidas en los últimos tiempos $(2,3)$.

La sepsis y el shock séptico constituyen, sin duda, una realidad clínica en la que los mediadores químicos de la inflamación propios del organismo desempeñan un papel relevante en su explicación fisiopatológica. Dentro de la biología quirúrgica el estudio de estos mediadores es donde quizás estén siendo más evidentes los avances en biología molecular y celular. El actual interés que ha suscitado este estudio no nos debe sorprender y ello se debe, fundamentalmente, a dos razones. Por un lado, una gran parte de la morbimortalidad asociada con la práctica quirúrgica diaria es debida a anomalías en la respuesta inflamatoria; por el otro, es cada vez más patente en la patogenia de afecciones tan dispares como la artritis reumatoide, el asma bronquial, el infarto cerebral o el síndrome de distrés respiratorio del adulto, todas ellas, pertenecientes a distintas especialidades médico-quirúrgicas, la alteración en la síntesis de tales mediadores (4).

Trabajo aceptado: 23 de Abril de 2001

Correspondencia: Hipólito Durán Giménez-Rico. Servicio de Cirugía General. Hospital del Bierzo. c/ la Dehesa s/n. 24411 Ponferrada. León. 
Por otra parte, en un mundo sanitario como el actual, en el que parece que la calidad asistencial solo atiende a cifras y números, éste es también un episodio de primera magnitud. No es de extrañar, si atendemos a un estudio reciente que estima en 81400 millones de pesetas la cifra que es necesaria invertir en el tratamiento de los 70000 nuevos casos de sepsis al año en nuestro país, de los que un 40\% (29600) presentarán un shock séptico y un $35 \%$ (26000) fallecerán (2). Puesto que es un problema de tiempo que dispongamos de tratamientos efectivos que disminuyan la morbimortalidad de un síndrome tan grave, y que es razonable pensar que su costo sea elevado, asistiremos posiblemente a un dilema entre lo económicamente posible y lo éticamente obligado.

\section{CONCEPTO}

Como primera premisa es referencia obligada la cita de la Conferencia de Consenso que reunió conjuntamente en agosto de 1991 a las sociedades norteamericanas The American College of Chest Physicians (ACCP) y The Society of Critical Care Medicine (SCCM) (5), con la firme intención de unificar criterios en torno a diferentes conceptos, todos ellos relacio- nados y considerados como definiciones previas de la sepsis y de las fases que la preceden y que, en su caso, la prosiguen hasta llegar al shock séptico. Éstos son: septicemia, sepsis, sepsis grave, shock séptico y síndrome de la respuesta inflamatoria sistémica (SRIS) (Tabla I).

La utilización de tales definiciones introduce una evolución progresiva de la gravedad en la sepsis entendida desde la infección como primer eslabón, hasta el shock séptico como el último y definitivo. Esta idea queda de manifiesto al comprobar una creciente coexistencia de eventos que comprometen la vida del enfermo (hemocultivos positivos, síndrome de distrés respiratorio del adulto, coagulación intravascular diseminada, insuficiencia renal), conforme avanzamos en el espectro de definiciones (6).

No cabe duda acerca del esfuerzo empleado por la Conferencia de Consenso del ACCP/SCCM para armonizar criterios, y permitir así, acabar con la lacra que ha caracterizado a las diferentes publicaciones médicas vertidas para evaluar el efecto de diversas medidas terapéuticas aplicadas en la sepsis y el shock séptico - la falta de definición en la selección de grupos homogéneos de pacientes - y por ella, concluir grandes diferencias de mortalidad (10-90\%) en sus resultados (7).

TABLA I

DEFINICIO NES DE SEPSIS Y TRASTO RNOS ASO CIADO S A LA SEPSIS

Septicemia Conjunto de situaciones clínicas en las que se encuentran microorganismos en la sangre. Este término es ambiguo y se recomienda su eliminación.

Respuesta inflamatoria sistémica a diversos estímulos (traumatismo, infección).

Síndrome de respuesta inflamatoria sistémica (SRIS)

Sepsis

Sepsis grave

Shock séptico
Su diagnóstico exige dos o más de las siguientes alteraciones:

1. Temperatura: $>38 \circ \mathrm{C} 0<360 \mathrm{C}$

2. Frecuencia cardíaca: $>90$ latidos/min

3. Frecuencia respiratoria: $>20$ respiraciones/min $0 \mathrm{PaCO}_{2}<32 \mathrm{~mm} \mathrm{Hg}$

4. Recuento leucocitario: $>12000 \mathrm{cel} / \mathrm{mm}^{3},<4000 \mathrm{cel} / \mathrm{mm}^{3} 0>10 \%$ de formas inmaduras

Respuesta sistémica a la infección. La infección se considera un fenómeno microbiano caracterizado por una respuesta inflamatoria a la presencia de microorganismos o la invasión de tejidos estériles del huésped por los microorganismos.

La respuesta sistémica a la infección se manifiesta por dos o más de

las siguientes alteraciones:

1. Temperatura: $>38^{\circ} \mathrm{C} 0<360 \mathrm{C}$

2. Frecuencia cardíaca: $>90$ latidos/min

3. Frecuencia respiratoria: $>20$ respiraciones/min o $\mathrm{PaCO}_{2}<32 \mathrm{~mm} \mathrm{Hg}$

4. Recuento leucocitario: $>12000 \mathrm{cel} / \mathrm{mm}^{3},<4000 \mathrm{cel} / \mathrm{mm}^{3} 0>10 \%$ de formas inmaduras

Sepsis asociada con disfunción orgánica, hipoperfusión o hipotensión. La hipoperfusión o las alteraciones de la perfusión pueden cursar con acidosis láctica (> $2 \mathrm{mmol} / \mathrm{l}$ ), oliguria $(<0,5 \mathrm{ml} / \mathrm{kg} / \mathrm{h}$ al menos durante $1 \mathrm{~h}$ ó $<$

$30 \mathrm{ml} / 2 \mathrm{~h}$ ) y alteraciones del estado mental (escala de Glasgow 11). La hipotensión se define como tensión arterial sistólica (TAS) $<90 \mathrm{~mm} \mathrm{Hg}$ o disminución de $>40 \mathrm{~mm} \mathrm{Hg}$ del valor basal en hipertensos con ausencia de otras causas conocidas de hipotensión.

Sepsis con hipotensión (TAS $<90 \mathrm{~mm} \mathrm{Hg}$ o disminución de $>40 \mathrm{~mm} \mathrm{Hg}$ del valor basal), a pesar de la adecuada resucitación con líquidos i.v., asociada con alteraciones de la perfusión, que pueden cursar, entre otros trastornos, con acidosis láctica (> 2 $\mathrm{mmol} / \mathrm{l})$, oliguria $(<0,5 \mathrm{ml} / \mathrm{kg} / \mathrm{h}$ al menos durante $1 \mathrm{~h}$ ó $<30 \mathrm{ml} / 2 \mathrm{~h}$ ) y alteraciones del estado mental (escala de Glasgow 11).

(Bone RC, Balk RA, Cerra FB y cols.: ACCP/SCCM Consensus conference: Definitions for sepsis and organ failure and guidelines for the use of innovative therapies in sepsis. Crit Care M ed 1992; 20: 864-874). 
No obstante, este problema semántico no parece todavía estar del todo resuelto y desde luego siguen surgiendo voces críticas que claman la necesidad de precisar todavía más el contexto clínico que envuelve al paciente con una sepsis (8-12). En efecto, según tales voces, las definiciones propuestas por la Conferencia de Consenso de la ACCP/SCCM adolecen de ser todavía demasiado amplias. Así, si para definir SRIS bastan dos criterios, cualquier paciente ingresado en la UCI presentaría tal patología al presentar una taquipnea superior a 20 respiraciones por minuto y una taquicardia de más de 90 latidos por minuto. En este sentido, en un estudio publicado en el año 1995 (13) de 3708 pacientes ingresados en tres UCIS y en tres plantas de hospitalización general, 2527 (68\%) cumplían criterios de SRIS y posiblemente, por tanto, se cometería un error al seleccionar a un grupo de población sin el suficiente riesgo para que se incluyan en estudios sobre sepsis.

Las conclusiones aportadas por un nuevo Consenso sobre sepsis, esta vez Europeo, y publicadas en 1994, pretendieron matizar más aún las definiciones aportadas tres años atrás por los norteamericanos y establecer con ello criterios más rigurosos en la selección de los pacientes que fueran a ser incluidos en los futuros ensayos clínicos destinados a evaluar las novedades terapeúticas en el shock séptico (14). Estas conclusiones quedan recogidas en la tabla II.

\section{TABLA II}

\section{CONSENSO EUROPEO SOBRE SEPSIS}

Importancia de la infección

\section{Importancia del} basal del paciente infección por VIH)

Importancia de la severidad de la sepsis

Importancia de la actitud terapéutica

\section{Es fundamental confimar la} existencia de infección severa. El foco infeccioso puede ser un factor pronóstico importante. Las presencia de bacteriemia tiene limitadas implicaciones.

La existencia de ciertas enfermedades debilitantes (cáncer, cirrosis hepática, puede condicionar de forma importante la evolución de los pacientes.

La severidad aguda de la sepsis es el factor pronóstico más importante. Puede ser evaluada por la presencia de shock séptico y/o disfunción orgánica y cuantificada por alguna escala de severidad

La actuación médico quirúrgica adecuada sobre el proceso infeccioso es un factor fundamental en la evolución del paciente.

An expert report of the European Society of Intensive Care M edicine: The problem of sepsis. Intensive Care M ed 1994; 20: 300-304).

\section{FISIOPATOLOGÍA DE LA SEPSIS. MEDIADORES ENDÓGENOS Y EXÓGENOS}

La sepsis es un fenómeno que comienza con la infección protagonizada por un microorganismo que invade al huésped atravesando sus barreras epiteliales (piel o mucosas). Antes de que los antibióticos se prodigasen, los microorganismos más frecuentes eran los grampositivos, especialmente el Strepto coccus pyogenes y el Staphylococcus aureus. Sin embargo, con la introducción paulatina de los antibióticos de amplio espectro los microorganismos gramnegativos (Echerichia coli, Klebsiella, Enterobacter, Proteus y Pseudomonas aeruginosa) fueron protagonizando la mayoría de las infecciones causantes de sepsis. En el momento actual, por la aparición de cepas de estafilococos resistentes a antibióticos, la incidencia de sepsis causada por ambos tipos de gérmenes parece haberse igualado en la mayoría de los hospitales. La sepsis y el shock séptico, por último, también pueden ser causados por virus, hongos, Rickettsias, protozoos o metazoos (15).

Si la respuesta inflamatoria del huésped es adecuada la infección se controla y los microorganismos o sus toxinas son eliminados o neutralizados. Sin embargo, si la respuesta es localmente insuficiente, ésta se perpetua por mecanismos moleculares que la tornan excesiva o incontrolada y acaban afectándose órganos distantes del foco infeccioso inicial. Estos mecanismos moleculares que, teóricamente, deberían tener finalidad defensiva, ponen de manifiesto la imperfección de un sistema inmunitario que en determinadas circunstancias se vuelve contra uno mismo de forma suicida (16).

El sistema inmunitario opera con elementos celulares que interactúan entre sí utilizando mediadores y receptores químicos. Una de las familias de mediadores mejor conocidas son las citoquinas proinflamatorias (Factor de necrosis tumoral [TNF], Inteleucina-1 [IL-1], Interleucina-6 [IL-6]), las cuales son liberadas a la circulación sanguínea y causan la activación de varias células, como neutrófilos, monocitos, macrófagos, plaquetas y células endoteliales. Así mismo, son también responsables de la activación de las cascadas proteicas plasmáticas: coagulación, fibrinolisis, complemento y calicreína-quinina; de mediadores lipídicos: eicosanoides (metabolitos del ácido araquidónico) y Factor activador de plaquetas (PAF); y por fin, de radicales de oxígeno y óxido nítrico. Pronto se comprobó que, de forma simultánea, en esta respuesta orgánica también se producían citoquinas antiinflamatorias (Interleucina-10 [IL-10]), antagonistas de citoquinas (antagonista del receptor de la IL-1 [IL-1Ra] y receptores solubles del TNF [sTNF-R]) $(17,18)$.

Consecuentemente, es importante acabar desterrando ideas pasadas que concebían la presencia de los microorganismos en la sangre como la principal causante de la morbimortalidad en la sepsis (19). Nadas más lejos de la realidad. Hoy día se sabe que la infección por sí misma no es la causa de las repercusiones sistémicas, sino que es la propia respuesta del organismo a la infección la que origina la mayoría de los problemas del paciente.

Desde un punto de vista fisiopatológico, la pregunta que cabe realizarse es cómo se interpreta una respuesta orgánica en la que se comprueba la presencia de elementos moleculares de signos contrarios: citoquinas proinflamatorias y antiinflamatorias. La teoría esgrimida por R.C. Bone (20) pretende aclarar la incógnita suscitada: la respuesta proinflamatoria intensa contribuye al inicio y al mantenimiento de la sepsis, pero también se produce una respuesta compensatoria antiinflamatoria que pretende restaurar la homeostasis. Cuando se produce una excesiva cantidad de mediadores proinflamatorios que apocan la respuesta antiinflamatoria el resultado sería una progresiva respuesta inflamatoria sistémica con fracaso multiorgánico. Por el contrario, una respuesta antiinflamatoria excesiva causaría inmunosupresión, que también sería consi- 
derada causa de fallo multiorgánico. Por lo expuesto, parece que el fracaso terapéutico estriba en la enorme dificultad que conlleva el equilibrio inmunológico entre dos fuerzas de sentido contrario que son estimuladas al mismo tiempo por un agente exógeno al individuo (21).

Estudiaremos a continuación, y de forma detallada, los diferentes mediadores, exógenos y endógenos, implicados en los mecanismos fisiopatogénicos de la sepsis y el shock séptico.

\section{MEDIADORES EXÓGENOS}

Endotoxina: la endotoxina o lipopolisacárido (LPS) es un componente estructural de la membrana externa de las bacterias gramnegativas y es el factor microbiano, entre los que activan la respuesta inflamatoria, mejor caracterizado y estudiado, considerándosele el mediador exógeno más importante del shock séptico (22-24). Estructuralmente está formada por dos dominios químicamente diferentes, uno hidrofílico (antígeno 0 y núcleo central) y otro hidrofóbico (lípido A). Este último, de composición semejante en todas las enterobacterias, es el principal responsable de la toxicidad del LPS (25).

Cuando la endotoxina es inyectada en animales de experimentación, provoca un estado muy parecido al del shock séptico, con hipotensión y disfunción orgánica. Este trastorno en la homeostasis hemodinámica está relacionado, en gran parte, con la liberación masiva de una amplia variedad de mediadores endógenos merced a la capacidad que tiene el LPS para unirse y activar diferentes tipos celulares (macrófagos, células endoteliales y plaquetas) y sistemas enzimáticos del medio extracelular (sistema del complemento, cascada de la coagulación y el sistema kalicreína-cinina) (26).

Más detalladamente, el LPS se puede unir a varias moléculas de superficie de células de mamíferos pero la única proteína de unión que le permite efectuar una señal funcional patológica en las células es CD14 que se expresa en monocitos, macrófagos, granulocitos y con menor intensidad en linfocitos B (27). En el plasma, el LPS puede unirse a proteínas como la proteína enlazante de LPS (LBP), formando un complejo que favorece y aumenta la sensibilidad del receptor CD14 al LPS (28). El resultado de la interacción LPS-receptor CD14 potencia la fosforilación y activación de quinasas intracelulares, en concreto, proteín tirosina quinasas (PTK) y MAP quinasa, del inglés, Mytogen Activated Protein quinasa. Las quinasas activadas modulan la expresión genética de la célula incrementando, en este caso, los niveles de ARN mensajero que codifican proteínas tales como las citoquinas, receptores de citoquinas, moléculas de adhesión, proteínas de fase aguda, factor tisular o la enzima sintasa NO (Óxido Nítrico) inducible $(29,30)$. Es decir, como resultado final se obtiene la liberación de mediadores que activan, intensifican y perpetúan la respuesta inflamatoria que de esta forma, puede volverse incontrolada.

Además de activar a monocitos, granulocitos y linfocitos B, LPS también estimula células CD14 negativas, como son las células endoteliales y los fibroblastos. Este efecto parece ser mediado por CD14 soluble que es liberado por los monocitos en dos formas: alfa y beta. Estas dos formas solubles de receptor permiten una función activadora a distancia.

Exotoxinas: los microorganismos habitualmente implicados en la secreción de exotoxinas con capacidad de provocar síndromes de hipotensión y de shock son el Staphyilococcus aureus (síndrome del shock tóxico provocado por la exotoxina TSST-1) y el Streptococcus pyogenes (exotoxina A). Las exotoxinas de ambos pertenecen al grupo de los superantígenos, dotados de una gran capacidad de estimulación del sistema inmunitario induciendo una importante proliferación no específica de linfocitos $\mathrm{T}$ y producción de citoquinas (31).

Peptidoglicanos: son compuestos elementales de la pared celular de todas las bacterias. La infusión de peptidoglicanos en animales de experimentación induce fiebre y cambios hemodinámicos comparables a los inducidos por la endotoxina, aunque de menor intensidad.

\section{MEDIADORES ENDÓGENOS}

Sistema del complemento: la activación del sistema del complemento en el shock séptico puede ser producida por LPS, por lesión directa extensa de los tejidos blandos, o por interacción con el sistema de coagulación (conversión de C1 a $\mathrm{C} 1$ activado por el factor Hageman activado) o con los sistemas fibrinolíticos (conversión de $\mathrm{C} 1$ a $\mathrm{C} 1$ activado por plasmina) (Fig. 1).

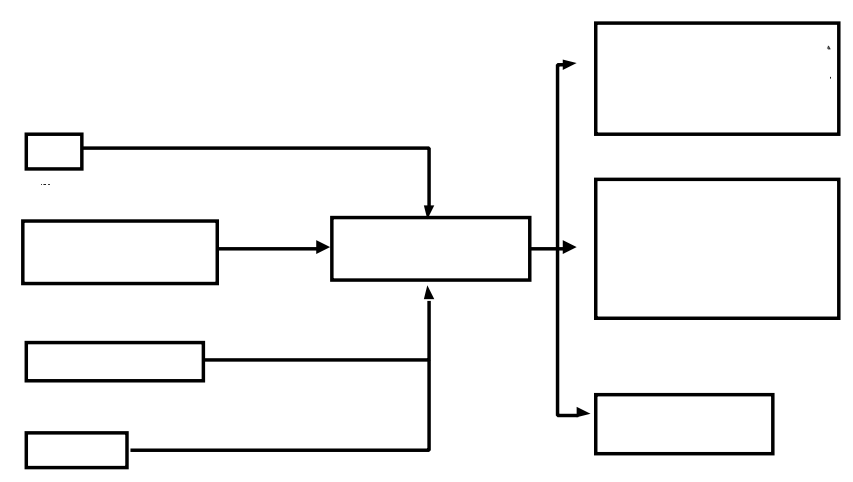

Fig. 1. Participación del sistema de complemento en la patogenia de la sepsis.

La activación del complemento es importante, porque aumenta la permeabilidad del endotelio y produce la degranulación de los mastocitos con liberación de sustancias vasodilatadoras (acciones mediadas por las anafilotoxinas C3a y C5a). Así mismo C5a es un potente quimioatrayente estimulando la migración, adherencia y agregación de las células polimorfonucleares con lo que potencia a los neutrófilos en su lesión oxidativa y proteolítica del endotelio.

Sistema de la coagulación: la sepsis se acompaña frecuentemente de coagulación intravascular diseminada (CID) (26). La consecuencia de este acontecimiento fisiopatológico sin freno puede ser fatal por el acúmulo de microtrombos en la microcirculación de cualquier órgano, que impiden la normal circulación de la sangre y el normal intercambio de oxígeno y nutrientes.

En su patogenia concurren $(32,33)$ : a) un aumento de la activación de la coagulación, b) una depresión de los mecanismos inhibidores de la coagulación, y c) una inhibición del sistema fibrinolítico (Fig. 2). 


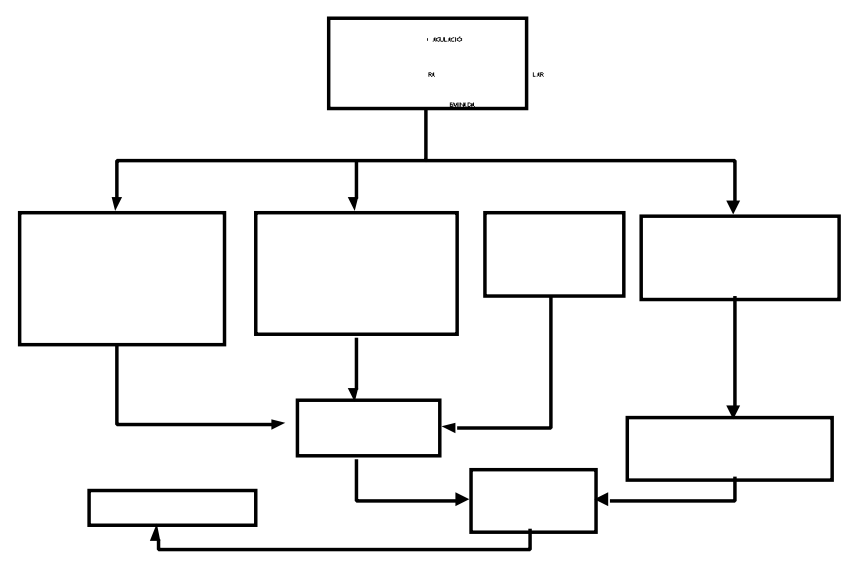

Fig. 2. M ecanismos de producción de la CID.

La cascada de la coagulación se activa, bien por la vía extrínseca, por medio del factor tisular producido por fagocitos mononucleares y las células endoteliales, o bien por la vía intrínseca, al activar el LPS directamente al factor Hageman.

Las alteraciones de la función de los mecanismos inhibidores de la coagulación se atribuyen a la disminución de antitrombina III (AT-III) y a la inhibición del sistema proteína Cproteína $\mathrm{S}$. AT-III es rápidamente consumido por la progresiva formación de trombina. La proteína $\mathrm{C}$ se activa mediante la formación de un complejo con trombina, trombomodulina, una proteína endotelial, y proteína S. En la sepsis, el TNF inhibe la síntesis de trombomodulina endotelial, por lo que disminuye la actividad antitrombogénica de la proteína C (34).

La inhibición del sistema fibrinolítico se debe al incremento en la concentración plasmática del inhibidor del plasminógeno activado tipo I (PAI-1), acontecimiento observado a la hora de la administración de LPS.

En la sepsis se produce un estado de máxima sensibilización de las plaquetas, responsable de que éstas expresen en su superficie moléculas de adhesión (35), que desempeñan una función fundamental en la agregación de las plaquetas entre sí y en su adhesión al endotelio vascular y a los neutrófilos. Estos conglomerados son retenidos en la microcirculación y agravan la perfusión de los órganos. Esta sensibilidad plaquetaria viene mediada por sustancias inflamatorias de fase agu$\mathrm{da}$, como fibrinógeno, derivados de proteína $\mathrm{C}$ reactiva, complemento e IL-6.

En la agregación plaquetaria al endotelio también participa activamente el endotelio mediante la expresión de endotelina-1 (ET-1) (36). ET-1 induce la liberación de factor Von Willebrand por las células endoteliales que contribuye a la adherencia de la plaqueta al endotelio. Además ET-1 estimula la actividad fosfolipasa y la liberación de Tromboxano A2, conocido factor por favorecer la vasoconstricción y la agregación plaquetaria.

Asimismo en la sepsis se produce el factor activador plaquetario (PAF), fosfolípido producido por numerosas células como macrófagos, neutrófilos, plaquetas y células endoteliales en respuesta a diferentes estímulos tanto inmunológicos como no inmunológicos. Entre sus efectos se citan la inducción de agregación plaquetaria y trombosis intravascular (Fig. 3).

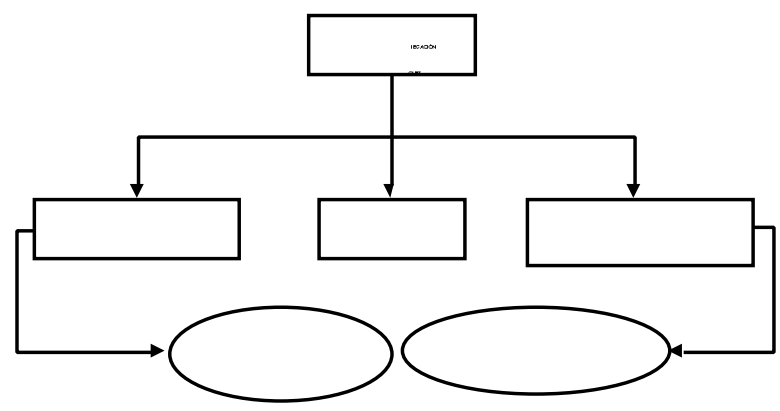

Fig. 3. M ecanismos de producción de la agregación plaquetaria.

Sistema Kalicreína-cinina: la activación del sistema de contacto de la coagulación (vía intrínseca de la coagulación, mediada por el LPS al activar al factor XII de Hageman) genera bradicinina a partir de cininógeno. La bradicinina es un potente hipotensor, acción mediada por el óxido nítrico y la prostaciclina liberados por el endotelio vascular, inducido por la bradicinina (Fig. 4).

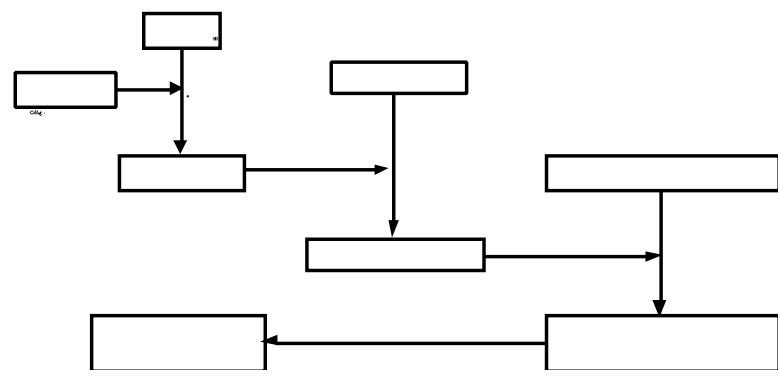

Fig. 4. Mecanismos de producción de la bradiquinina.

Metabolitos del ácido araquidónico: el LPS estimula la capacidad de los macrófagos para producir metabolitos del ácido araquidónico (37), genéricamente denominados eicosanoides, bien por la vía de la ciclooxigenasa sintetizándose las diferentes prostaglandinas (PG) y tromboxanos (TX), bien por la vía de la lipooxigenasa produciéndose los leucotrienos (LT). Este efecto podría estar mediado por la activación directa de la fosfolipasa de membrana por parte del TNF-alfa. Como mecanismo de retroalimentación, estos eicosanoides han demostrado in vitro su capacidad de modular la producción de citoquinas, así como alguno de los efectos de dichas sustancias sobre las células diana (17).

Los principales eicosanoides hoy día implicados en la mediación de los efectos de la endotoxina son el Tromboxano $\mathrm{A}_{2}\left(\mathrm{TXA}_{2}\right)$, la prostaciclina $\left(\mathrm{PGI}_{2}\right)$, la prostaglandina $\mathrm{E}_{2}$ $\left(\mathrm{PGE}_{2}\right)$ y el leucotrieno $\mathrm{B}_{4}\left(\mathrm{LTB}_{4}\right)$.

Citoquinas: cuando se descubrió en 1985 que una citoquina, TNF-alfa, producía los mismo síntomas que la endotoxemia, esto es, fiebre, hipotensión arterial, acidosis metabólica, hipertrigliceridemia y taquicardia la investigación se polarizó hacia el estudio de las citoquinas como mediadores centrales en las consecuencias deletéreas de la infección $(38,39)$.

Según mencionamos anteriormente, en la infección incontrolada que ocasiona una sepsis existe una liberación simultá- 
nea de citoquinas de signos contrapuestos: proinflamatorias y antiinflamatorias. Es, precisamente, la falta de equilibrio en la secreción de las mismas el detonante, si no se detiene a tiempo, que conduce a los dos grandes trastornos hemodinámicos precursores del fallo irreversible en cadena de todos los órganos de la economía: el fallo cardíaco como bomba y la alteración de la microcirculación.

Las citoquinas proinflamatorias TNF-alfa e IL-1 son los principales mediadores endógenos de la sepsis $(40,41)$. Ambas citoquinas tienen diferente estructura y receptores aunque sus actividades biológicas se superponen y son sinérgicas. El TNF-alfa es secretado mayoritariamente por los macrófagos estimulados por la endotoxina, si bien también puede ser sintetizado por otras células como monocitos, mastocitos, células Kupffer, astrocitos, estimulados, no sólo por la endotoxina sino también por exotoxinas, virus, antígenos de hongos y parásitos, fracción C5a del complemento y complejos antígeno anticuerpo. Existen dos formas de IL-1: alfa y beta, que se unen a los mismos receptores y tienen idénticos efectos biológicos. La forma alfa rara vez se encuentra en los líquidos corporales en forma soluble, al contrario que la forma beta. En la sepsis la forma beta alcanza elevadas concentraciones plasmáticas, aunque por lo regular son inferiores a las que alcanza el factor TNF-alfa.

Una propiedad fundamental de estas citoquinas proinflamatorias es inducir en las células que activan la expresión de una variedad de genes que implican a la microcirculación y al ambiente tisular más próximo (17). Es decir, "genes inflamatorios", cuya activación traduce la síntesis de otros miembros de la familia de las citoquinas y la síntesis de enzimas encargadas, a su vez, de la regulación de mediadores inflamatorios de pequeño peso molecular. Tales mediadores son las prostaglandinas, los leucotrienos y el óxido nítrico.

En este sentido, la IL-1 y el TNF-alfa son potentes inductores de la expresión genética que codifica la síntesis de fosfolipasa $\mathrm{A}_{2}$ tipo 2 y la ciclooxigenasa-2, enzimas, ambas, determinantes en la síntesis de prostaglandinas y leucotrienos (37). Ensayos clínicos con humanos en los que se administró dosis reducidas de IL-1 y TNF-alfa advirtieron que éstos experimentaban fiebre, dolores de cabeza y artromialgias, síntomas que se desvanecían con la administración de un antiinflamatorio inhibidor de la ciclooxigenasa (42). Adicionalmente, la IL-1 y el TNFalfa son potentes inductores de la expresión genética que codifica la síntesis de sintasa NO inducible, con el correspondiente aumento en la producción endotelial de NO, máximo responsable de la hipotensión vascular que acontece en la sepsis (43-45).

La IL-6, también citoquina proinflamatoria, aumenta en el plasma de los pacientes con sepsis y sus concentraciones más elevadas se encuentran en los casos de shock séptico (46). Curiosamente, sí existe una correlación entre la severidad del cuadro clínico de la sepsis y el nivel de esta citoquina en la sangre; dato, que no se aprecia al considerar los niveles de TNF-alfa e IL-1.

Resulta contradictorio el papel de esta citoquina, cuyos niveles en plasma son proporcionales a la severidad del cuadro clínico, pero cuyas funciones biológicas no parecen dotarla de un papel primordial en la activación de la respuesta inflamatoria. Así, se observa "in vitro" que lejos de potenciar la síntesis de PGD, la frena mediante la supresión de la expresión genética celular de la ciclooxigenasa (47-49).

En conclusión, a pesar del aparente efecto beneficioso de la IL-6 frenando la síntesis de mediadores intermedios de la inflamación, ¿cómo es posible que sea la citoquina cuyos niveles sanguíneos elevados se relacionan de una forma más directa con la gravedad del cuadro?. Sin duda, nos encontramos ante un dilema pendiente de solución.

El aumento de la producción y liberación de las citoquinas proinflamatorias se acompaña de la elevación plasmática de las concentraciones de citoquinas antiinflamatorias y de antagonistas de las citoquinas(50).

Dentro de las citoquinas antiinflamatorias cabe destacar a la IL-4, la IL-10, la IL-13 o el Factor transformador de crecimiento beta (TGF-beta). Todas ellas suprimen la expresión genética de las citoquinas inflamatorias, IL-1 y TNF-alfa. Junto a éstas existe además en la sepsis una expresión aumentada de antagonistas de las citoquinas. Entre ellos es obligado citar a los antagonistas del TNF-alfa llamados receptores solubles de TNF (sTNF-I y sTNF-II)(51) y a un antagonista natural de IL-1, que es el antagonista de su receptor, el IL-1ra $(52,53)$. Los primeros, son fragmentos de dos receptores de TNF de membrana que se liberan en la circulación y al unirse a TNFalfa inhiben sus actividades biológicas. El segundo, es un miembro de la familia IL-1 que se libera en la circulación sanguínea e impide que IL-1 se una a sus receptores.

Desgraciadamente, estos efectos aparentemente apaciguadores atribuidos a los antagonistas de las citoquinas, demostrados ampliamente "in vitro", no se han sucedido de éxitos terapéuticos cuando han sido testados en diferentes estudios randomizados dobles ciego $(2,4,54,55)$. Un argumento frecuentemente barajado para tales resultados es la falta de precocidad en la aplicación de las terapias que son ensayadas (21). En efecto, desafortunadamente los signos clínicos habitualmente reveladores de una sepsis son secundarios a la propia respuesta productora de citoquinas del huésped; en consecuencia, reducir su síntesis una vez han hecho acto de presencia resulta inútil, por cuanto en este momento, las citoquinas ya han "explotado" el complejo sistema inflamatorio del organismo.

Radicales libres, radicales tóxicos de oxígeno: en el shock establecido la infusión de líquidos en altos volúmenes logra, en ocasiones, remontar una precarga adecuada y con ello una perfusión de tejidos que hasta el momento se encontraban en situación isquémica. Este fenómeno de isquemia-reperfusión activa en el seno de las células endoteliales ciertos sistemas enzimáticos de oxidación ajenos a las mitocondrias, por ejemplo el de la xantinaoxidasa, con la consiguiente conversión de oxígeno molecular a radicales tóxicos de oxígeno, en particular, el anión superóxido y el radical hidroxilo $(6,7)$. Tales agentes oxidantes inducen lesión tisular directa (destrucción de enzimas, lesión de ADN, degradación del colágeno, depolimerización y peroxidación de lípidos). La producción de radicales libres puede también ser importante en otras estirpes celulares como los neutrófilos, los monocitos y los macrófagos.

Adicionalmente, la revascularización del tejido isquémico es responsable de una interacción leucocito-endotelial que conlleva, ulteriormente, una migración transendotelial del leucocito y con ello, la liberación de sus factores lesivos para los tejidos circundantes. Esta interacción leucocito-endotelial es inicialmente laxa, adhesión por rodadura, debida a la interacción entre selectinas del endotelio y del leucocito. Seguidamente, la fijación se convierte en adhesión fuerte cuando los neutrófilos expresan en su superficie unas moléculas llamadas integrinas (CD11 y CD18) que se unen a inmunoglobulinas endoteliales (ICAM-1 e ICAM-2) (36,56). En la expresión de 
las citadas moléculas de adhesión por parte de las células endoteliales y los neutrófilos intervienen activamente el LPS, el TNF y la IL-1 (57). Por último, en esta interacción leucocito-endotelio también participa la endotelina-1 (ET-1) (36), aunque como vimos anteriormente, su papel era más significado en la inducción de los microtrombos circulatorios por favorecer la agregación entre las plaquetas y el endotelio.

Óxido Nítrico $(N O)$ : la síntesis del NO por la célula endotelial, catalizada por la familia de las NO sintetasas a partir del aminoácido L-arginina, es responsable del tono vasodilatador, esencial para la regulación de la tensión arterial y una síntesis excesiva puede ser responsable de la hipotensión refractaria del shock séptico. El LPS, y las citoquinas proinflamatorias estimulan la liberación masiva endotelial de esta sustancia por inducir la expresión de una isoforma, diferente de la habitual, de la enzima sintetasa de $\mathrm{NO}(45)$.

Además, esta liberación desmesurada de NO desencadena un mecanismo de actuación diferente del habitual (Fig. 5). En condiciones fisiológicas, el NO ejerce sus efectos mediante la activación de la fracción soluble de la enzima guanilato ciclasa, con el consiguiente aumento en la concentración del segundo mensajero guanosina monofosfato cíclico (cGMP). En este nuevo marco hiperproductor, el NO actúa independientemente de la cGMP, bien sea aumentando la ribosilación de ADP en las proteínas plaquetarias, inactivando enzimas mitocondriales, o dañando el ADN, en definitiva, causando daño celular intenso irreversible en la microcirculación (58).

Resumir con una frase la compleja interacción existente entre el conjunto de todos los mediadores en la patogenia de la sepsis supone un verdadero ejercicio de compilación, reservado, desde luego, para mentes privilegiadas. Por ello, me he permitido concluir este apartado con una cita textual de Arthur P. Wheeler (16) que satisface sobradamente este cometido: "la fisiopatología de la sepsis implica un estímulo tóxico inicial, por ejemplo la endotoxina, que desencadena la pro ducción masiva de citoquinas proinflamatorias, TNF-alfa y IL1, las cuales inducen a su vez la adhesión leucocito-endotelial, la activación de la coagulación y la generación de otros y numerosos mediadores secundarios de la inflamación, inclui das otras citoquinas, leucotrienos, prostaglandinas y protea sas. Así mismo no hay que desdeñar la secreción de citoquinas antiinflamatorias IL-6 e IL-10, que pudieran modular la res puesta inflamatoria, pero que en definitiva, son secretadas con un signo desequilibrante, bien por defecto o bien por exceso".

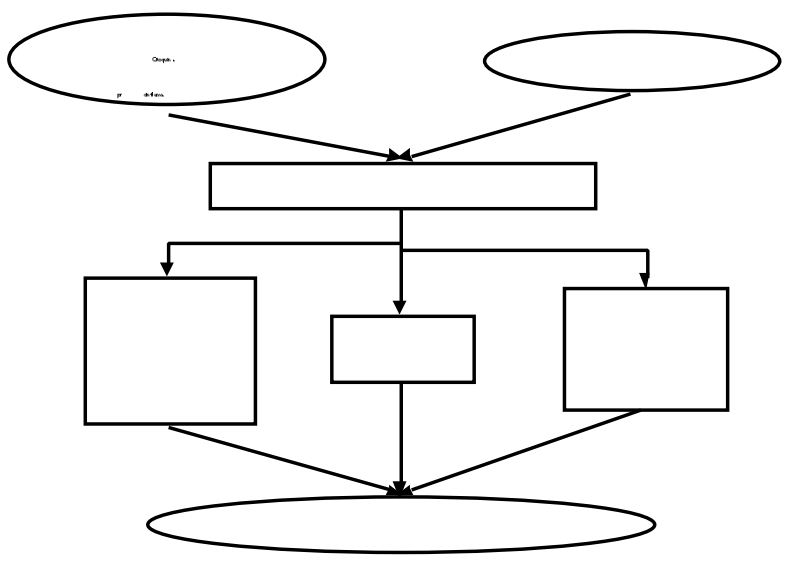

Fig. 5. Efectos nocivos del NO.

\section{TRATAMIENTO DE LA SEPSIS}

"Debemos cambiar las fórmulas de actuación" (59). Con esta frase lapidaria tan pesimista titula Stanley A. Nasraway una revisión sobre las distintos principios activos empleados en el tratamiento de la sepsis (Tabla III), muchos de ellos todavía en fase de investigación, que han protagonizado diferentes artículos originales de otras tantas revistas médicas de prestigio. Así las cosas, para frustración de los investigadores que han conducido tales ensayos en humanos, aunque cada uno de ellos había sido eficaz en modelos animales, ninguno se mostró inequívocamente beneficioso en pacientes sépticos.

En la citada revisión, el autor enumera hasta 11 causas por las cuales, y siempre según su criterio, los resultados vertidos por los ensayos clínicos (28 con carácter prospectivo) aplicados al tratamiento de la sepsis en humanos son tan calamitosos. Sin duda, la que parece más importante de todas ellas es la inadecuada selección de los pacientes en la elaboración de los grupos que formarán parte de los ensayos $(10,12,59)$. No parece coherente incluir en la misma partida enfermos atendiendo sólo a criterios clínicos tales como la presencia de fiebre, leucocitosis, taquipnea o taquicardia, en esencia, aquellos que constituyen la definición de sepsis. En efecto, aunque presentes todos ellos en dos enfermos, sería lógico considerarles en grupos estancos completamente diferentes, cuando el primero, por ejemplo, padeciera una infección por gramnegativos y en el segundo, fuera por grampositivos. Situación similar nos encontraríamos cuando en el primero primara un patrón bioquímico de mediadores proinflamatorios y en el segundo, primara uno antiinflamatorio. Concluyendo, si nos atenemos a grupos homogéneos, el número de enfermos a incluir en los ensayos será menor, pero desde luego, los resultados serán más fiables y por tanto de mayor consideración.

Junto a este defecto de forma se ha insistido en otro, de fondo, que resulta inicialmente mucho más desalentador (11). ¿Sabemos tanto de los mecanismos etiopatogénicos de la sepsis como para afirmar que nuestras investigaciones van por buen camino?. ¿Es cierto que la cascada inflamatoria desenfrenada es el verdadero promotor del fallo orgánico?. ¿Qué importancia tiene el equilibrio entre mediadores proinflamatorios y mediadores antiinflamatorios?. La contestación certera a tales preguntas, si algún día llega, pudiera servir como simiente para las futuras aplicaciones terapeúticas. El presente parece ofrecer pocas alternativas y lo cierto por el momento, es que las medidas de soporte hemodinámico y pulmonar, tan avanzadas, son la única moneda válida para vencer a esta enfermedad.

Un tercer problema crucial con estas terapeúticas es el momento de instaurarlas(21); tal como ocurre con los antibióticos peroperatorios, los antagonistas de los mediadores inflamatorios han sido eficaces sobre todo cuando se dieron antes del comienzo de la sepsis. Algo inusual en la sepsis, ya que su diagnóstico consiste en certificar un conjunto de signos que no son más que la propia respuesta productora de citoquinas del huésped.

$\mathrm{Al}$ respecto de estos problemas, cabe recordar a J.L. Vincent (21) cuando escribe: "las estrategias inmunomodulado ras alcanzarán cotas de éxito cuando se aplique la droga oportuna, en el enfermo apropiado, en su justa dosis y en el preciso momento".

En suma, actualmente el tratamiento de la sepsis se enfoca bajo dos puntos de vista: el tratamiento etiológico, de 
TABLA III

ESTRATEGIAS TERAPÉUTICAS EM PLEADAS EN LA SEPSIS

\begin{tabular}{ll}
\hline Principio activo & Fundamento terapéutico \\
\hline Esteroides & Inhiben la síntesis de citoquinas en los monocitos \\
Anticuerpos antiendotoxina & Neutralizan la endotoxina \\
Compuestos antioxidantes & Neutralizan los efectos perjudiciales de los radicales tóxicos de oxígeno \\
Antagonistas del óxido nítrico & Restablecen un adecuado tono vasorregulador \\
Anticuerpos antiTNF-alfa & Inactivan la citoquina TNF-alfa \\
Receptores solubles de TNF-alfa & Ligan la citoquina TNF-alfa soluble y evitan que ésta se una a sus receptores de membrana celular \\
Anticuerpos antirreceptor de TNF-alfa & Compiten con la citoquina TNF-alfa por la unión a sus receptores de membrana celular \\
Antagonistas de los receptores de la IL-1 & Compiten con la citoquina IL-1 por la unión a sus receptores de membrana celular \\
Anticuerpos antiCD-14 & Impiden la unión de la endotoxina a sus receptores de membrana \\
Inhibidores de la proteincinasa & Impiden la función del mensajero intracelular (proteincinasa) en la síntesis celular de citoquinas \\
Bloqueantes del gen NF-kappa-beta & Terapia génica inhibidora de la señal de transducción en la síntesis celular de citoquinas \\
Inhibidores de la ciclooxigenasa & Bloquean la producción de PGD pirógenas, de tromboxano y de prostaciclina \\
Terapia anticoagulante & Inhiben la formación de microtrombos y con ello, evitar el daño tisular debido a fenómenos \\
(antitrombina III y uroquinasa) & de isquemia y reperfusión \\
Antagonistas del tromboxano & Inhiben la vasoconstricción y la agregación plaquetaria \\
Antagonistas del FAP & Bloquean la activación y la agregación plaquetaria \\
Inhibidores de las moléculas de adhesión & Impiden la interacción leucocito-endotelio \\
Pentoxifilina (inhibidor de la fosfodiesterasa) & Aumenta la producción de AM Pc y con ello, disminuir la producción de TNF-alfa, inducir \\
& vasodilatación y reducir la agregación plaquetaria. \\
\hline
\end{tabular}

escasa o nula repercusión clínica, que busca diferentes estrategias que puedan modular la batería de mediadores activada y consecuentemente, frenar la respuesta inflamatoria exagerada, y el tratamiento de soporte, hoy por hoy verdadero y único protagonista en la realidad asistencial de los hospitales, que en esencia, se centra en cuatro aspectos. El primero, consiste en el control de la infección con la administración precoz de los antibióticos apropiados y la eliminación de focos sépticos (drenaje de abscesos, retirada de catéteres y prótesis contaminadas); el segundo, en controlar la hemodinámica cardiovascular mediante la terapia hidroelectrolítica y uso de fármacos inotrópicos y vasoactivos; el tercero, pretenderá el control de la ventilación y oxigenación de la sangre, que no en raras ocasiones requiere el empleo de respiradores artificiales, y finalmente, el cuarto, proporcionará un adecuado aporte nutricional.

\section{Bibliografía}

1. León C, Vilches P, Sánchez MA, Lucena F: Nuevos conceptos de sepsis y síndrome séptico. Correlato etiológico. Rev Clin Esp 1996; 196 (Monográfico): 27-31.

2. Torrabadella P, Salgado A: Nuevos tratamientos de la sepsis grave. Una encrucijada científica, económica y ética. Med Clin (Barc) 1999; 113: 18-19.

3. Gómez J, Salgado A: Sepsis, asignatura pendiente para el siglo XXI. Med Clin (Barc) 1995; 105: 304-307.

4. Balibrea JL, Arias J: Shock séptico: de la investigación básica a la cabecera del enfermo. Rev Clin Esp 1995; 195 (6): 363-365.

5. Bone RC, Balk RA, Cerra FB, et al: ACCP/SCCM Consensus conference: Definitions for sepsis and organ failure and guidelines for the use of innovative therapies in sepsis. Crit Care Med 1992; 20: 864-874.

6. Arias J, Aller MA, Arias JI, Lorente L, Durán HJ, Durán MC, Monterde G, Rodríguez G, Rodríguez J, Tovar JA. Sepsis. En: Arias J, et al. "Fisiopatología Quirúrgica: Traumatismos, Infecciones, Tumores".Editorial Tébar. Madrid 1999; 377-440.

7. Arias J. Sepsis y shock séptico. Cir Esp 1996; 60 Suppl 2: 22-33.

8. Abraham E, Matthay M, Dinarello C, Vincent J, Cohen J, Opal S, Glauser M, Parsons P, Fisher C, Repine J. Consensus conference definitions for sepsis, septic shock, acute lung injury, and acute respiratory distress syndrome: time for a reevaluation. Crit Care Med 2000; 28 (1): 232-235.

9. Muckart DJJ, Bhagwanjee S. ACCP/SCCM Consensus conference definitions of the systemic inflammatory response syndrome and allied disorders in relation to critically injured patients. Crit Care Med 1997; 25: 1789-1795.

10. Bossink AWJ., Groeneweld ABJ, Hack CE, et al. Prediction of mortality in febrile medical patients. How useful are Systemic Inflammatory Response Syndrome and sepsis criteria?. Chest 1998; 113: 1533-1541.

11. Vincent JL. Dear SRIS. I'm sorry that I don't like you. Crit Care Med 1997; 25: 372 .

12. Opal SM. The uncertain value of the definition for SRIS. Chest 1998; 113: 1442-1443.

13. Rangel Frausto MS, Piltet D, Cortigan M, Hwang T, Davis CS, Wenzer RP. The natural history of the Systemic Inflammatory response Syndrome (SIRS). A prospective study. JAMA 1995; 273: 117-123.

14. An expert report of the European Society of Intensive Care Medicine: The problem of sepsis. Intensive Care Med 1994; 20: 300-304.

15. Carcillo JA, Cunnion RE. Septic shock. Crit Care Clin 1997; 13: 553-574.

16. Wheeler A, Bernard G. Treating patients with severe sepsis. N Engl J Med 1999; 340 (3): 207-214.

17. Dinarello C. Proinflammatory and antiinflammatory cytokines as mediators in the pathogenesis of septic shock. Chest 1997; 112 Suppl 6: 321-329. 
18. Antonelli M. Sepsis and septic shock: proinflammatory or antiinflammatory state?. J Chemoter 1999; 11 (6): 536-540.

19. Pollock AV. At what point is infection cured but inflammation persists? Eur J Surg 1996; Suppl 576: 13-15.

20. Bone RC. Sepsis and SRIS. Nephrol Dial Transplant 1994; 9 Suppl 4: 99-103.

21. Vincent J. Search for effective immunomodulating strategies against sepsis. Lancet 1998; 351: 922-923.

22. Hoffman WD, Natanson C. Endotoxin in septic shock. Anesth Analg 1995; 81: 1123-1124.

23. Michie HR, Movogne KR, Spriggs DR, et al: Detection of circulating tumor necrosis factor after the endotoxin administration. N Engl J Med 1988; 318: 1481-1486

24. Morrison DC, Ryan JL. Endotoxins and disease mechanisms. Ann Rev Med 1987; 38: 417-432.

25. Tobias PS, Ulevitch RJ. Lipopolysaccharide binding protein and CD14 in the lipopolysaccharide dependent activation of cells. Chest 1994; 105 Suppl 3: 485-503.

26. Hardaway R. A review of septic shock. Am Surg 2000; 66 (1): 22-29.

27. Wenzel RP, Pinsky MR, Ulevitch RJ, Young L. Curent understanding of sepsis. Clin Infect Dis1996; 22: 407-413.

28. Tobias PS, Soldau K, Gegner JA, Muntz D, Ulevitch RS. Lipopolysaccharide binding proteins mediated complexation of lipopolysaccharide with soluble CD14. J Exp Med 1986; 164: 777-793.

29. Derijard B, Raingeaud J, Barrett T, et al. Independent human MAP kinase signal transduction pathways defined by MEK and MKK isoforms. Science 1995; 267: 682-685.

30. Lee JC, Laydon JT, Mc Donnell PC, et al. A protein kinase involved in the regulation of inflammatory cytokine biosynthesis. Nature 1994; 372: 739-746.

31. Hackett SP, Stevens DL. Superantigens associated with staphhylococcal toxic shock syndrome are potents inducers of tumor necrosis factor beta synthesis. J Infect Dis 1993; 168: 232-237.

32. Bone RC. Modulators of coagulation. A critical appraisal of their role in the sepsis. Ann Intern Med 1992; 152: 1381-1389.

33. Levi M, Van der Poll T, Tenlate H, Van Deventer SJH. The cytokine mediated imbalance between coagulant and anticoagulant mechanisms in sepsis and endotoxaemia. Eur J Chim Invest 1997; 27: 3-9.

34. Van der Poll T, Buller HR, Tenlate H. Activation of coagulation after administration of tumor necrosis factor to normal subjects. N Engl J Med 1990; 322: 1622-1627.

35. Gawaz M, Dickfield T, Bogner C, Fateh Moghadam S, Neumann FJ. Platelet function in septic multiple organ dysfunction syndrome. Intensive Care Med 1997; 23: 379-385.

36. Cowley H, Heney D, Gearing A, Hemingway I, Webster N. Increased circulating adhesion molecule concentrations in patients with the systemic inflammatory response syndrome: a prospective cohort study. Crit Care Med 1994; 22: 651-657.

37. Wheeler AP, Hardie WD, Bernard GR. The role of cycolooxigenase products in lung injury induced by tumor necrosis factor in sheeps. Am Rev Repir Dis 1992; 145: 632-639.

38. Beutler B, Milsark IW, Cerami A. Passive immunization against cachectin tumor necrosis factor protects mice from the lethal effect of endotoxin. Science 1985; 229: 869-871.

39. Lin E, Calvanos S, Lowry S. Inflammatory cytokines and cell response in surgery. $2000 ; 127: 117-126$.
40. Dinarello C. Cytokines as mediators in the pathogenesis of septic shock. Curr Topics Microbiol Inmunol 1996; 216: 133-165.

41. Damas P, Canivet JL, De Groote DD, Vrindts Y, Albert A, Franchimon P, Lamy M. Sepsis and serum cytokine concentrations. Crit Care Med 1997; 25: 405-412.

42. Bernard GR, Wheeler AP, Russel JA, et al. Effect of ibuprofen in the physiology and survival on patients with sepsis. N Engl J Med 1997; 336: 912-918.

43. Moncada S, Palmer RMJ, Higgs EA. Nitric Oxide: physiology, pathophysiology and pharmacology. Pharmacol Rev 1991; 43: 109-142.

44. Lorente J, Landín L, Pablo R, Renés E, Liste E. L arginine pathway in sepsis syndrome. Crit Care Med 1993; 21: 1287-1295.

45. Cobb J, Danner R. Nitric Oxide and septic shock. JAMA 1996; 275: 1192-1196.

46. Dinarello CA, Cannon JG, Manille J, et al. Interleukin 6 as an endogenous pyrogen: induction of prostaglandin E2 in brain but not in peripheral blood mononuclear cells. Brain Res 1991; 562: 199-206.

47. Cassey LL, Balk RA, Bone RC. Plasma cytokines and endotoxin levels correlate with survival in patients with the sepsis syndrome. Ann Intern Med 1993; 119: 771-778.

48. Haptmann B, Van Damme J, Bayer JM. Modulation of IL-1 inflammatory and inmmunomodulatory properties of IL-6. Eur Cytokine Netw 1991; 2: 39-46.

49. Schindler R, Movilla J, Enover S, Glarbain R, Clark SC, Dinarello CA. Correlations and interactions in the production of interleukine 6 (IL-6), IL-1 and the TNF in human blood mononuclear cells: IL-6 supresses IL1 and TNF. Blood 1990; 75: 40-47.

50. Chernoff AE, Granowitz EV, Shapiro L, et al. A randomized controlled trial of IL-10 in humans: inhibition of inflammatory cytokine production and inmune responses. J Inmunol 1995; 154: 54925499.

51. Olsson I, Gatanaga T, Gullberg U, et al. TNF binding proteins (soluble TNF receptors forms) with possible roles in inflammation and malignancy. Eur Cytokine Netw 1993; 4: 169-180.

52. Dripps DJ, Brandhuber BJ, Thompson RC, et al. Effect of IL-1 ra on IL1 signal transduction. J Biol Chem 1991; 266: 10331-10336.

53. Hannum CH, Wilcox CJ, Arend WP, et al. IL-1 receptor antagonist activity of a human IL-1 inhibitor. Nature 1990; 343: 336-340.

54. Fisher CJJ, Dhainaut JF, Opal SM, et al. Recombinant human interleukin-1 receptor antagonist in the treatment of patients with sepsis syndrome: results from a randomized, double blind, placebo controlled trial. JAMA 1994; 271: 1836-1843.

55. Opal SM. Clinical trials of novel therapeutic agents: why did they fail? En Vincent JL, ed Yearbook of Intensive Care Medicine. Berlin: Springer Vellas 1995; 425-436.

56. Astiz M, de Gent G, Lin R, Rackow E. Microvascular formation and rheologic changes in hyperdinamic sepsis. Crit Care Med 1995; 23: 267-271.

57. Menger MD, Vollner B. Adhesion molecules as determinants of disease: from molecular biology to surgical research. Br J Surg 1996; 83: 588-601.

58. Moncada S, Palmer RMJ, Higgs EA. Biosynthesis of Nitric Oxide from $\mathrm{L}$ arginine. A pathway for the regulation of cell function and communication. Biochem Pharmacol 1989; 11: 1709-1715.

59. Nasraway S. Sepsis research: we must change course. Crit Care Med 1999; 27 (2): 427-430. 